\title{
Cyromazine and Chlorpyrifos Induced Renal Toxicity in Rats: The Ameliorating Effects of Green Tea Extract
}

\author{
Tarek M. Heikal' ${ }^{1}$ Abdel-Tawab H. Mossa ${ }^{1 *}$, Gehan I. Kh. Marei ${ }^{2}$ Mona A. Abdel Rasoul ${ }^{2}$
}

${ }^{1}$ Environmental Toxicology Research Unit (ETRU), Pesticide Chemistry Department, National Research Centre (NRC), Cairo, Egypt ${ }^{2}$ Department of Pest Control and Environmental Protection, Faculty of Agriculture, Damanhour University, Damanhour, Egypt

\begin{abstract}
In the present study, the protective effect of an aqueous extract of green tea (GT) against renal oxidative damage and nephrotoxicity induced by cyromazine (Cyr), chlorpyrifos (CPF) and their combination in male rats was undertaken. Eight groups containing six rats each were selected. Group I served as control. Groups II, III and IV rats were given a single daily oral doses of Cyr (169.35 mg kg-1 $1 / 20 \mathrm{LD}_{50}$, in corn oil), CPF $\left(6.75 \mathrm{mg} \mathrm{kg}^{-1} \mathrm{~kg}^{-1}, 1 / 20 \mathrm{LD}_{50}\right.$, in corn oil) and their combination for 28 consecutive days, respectively. Group V permitted free access to solubilised GT $(1.5 \% \mathrm{w} / \mathrm{V}$ in water) as the sole drinking fluid. Groups VI, VII and VIII rats were given the same doses as groups II, III and IV and simultaneously permitted free access to solubilised GT as the sole drinking fluid. Significant reduction in body weight and elevation in kidney weight were observed in insecticides exposed rats compared to control. Significant perturbations of renal function as evidenced via increase in blood urea nitrogen (BUN) and serum creatinine level were observed in treated rats. Also, renal oxidative damage was observed in insecticide-treated rats as evidenced via augmentation in kidney lipid peroxidation (LPO) as well as depletion in kidney antioxidant enzymes; catalase (CAT), superoxide dismutase (SOD) and glutathione peroxidase (GPx). Histopathological analysis of the kidney revealed that supplementation with GT resulted in nil to mild in vacuolization, swelling and degeneration in the endothelium of glomerular tuft and the epithelium of lining tubules. In conclusion, the use of green tea extract appeared to be beneficial to rats, to a great extent by attenuating and restoring the damage sustained by insecticide exposure.
\end{abstract}

Keywords: Cyromazine; Chlorpyrifos; Green tea; Oxidative stress; Renal toxicity; Rat

\section{Introduction}

Chlorpyrifos (CPF), a broad spectrum organophosphate insecticide (OPI), is one of the most extensively used OPIs in domestic and industrial applications all over the world [1]. CPF is classified as a moderately hazardous, Class II insecticide by the WHO [2]. CPF is thought to be primarily metabolized in the liver by multiple specific cytochrome P450 enzymes through several reaction pathways [3]. Like other OPIs, CPF is known to inhibit acethylcholinesterase activity in target tissues [4,5]. In addition, it is reported that CPF may effect other systems, including liver [6], lung [7], brain [8] and erythrocytes [4,9].

Cyromazine (Cyr), N-cyclopropyl-1,3,5-triazine-2,4,6-triamine, is an effective insect growth regulator that acts by inhibiting the moulting processes. It is wildly used as an agricultural insecticide and a feed additive to animal breeding against fly larvae from hatching in manure $[10,11]$. The early investigation showed that Cyr is harmless to mammals and poultry. However, it was proved to cause mammary tumors in the mouse [12]. Besides the amount of parent drug excreted through feces, a portion of Cyr (2-14\%) is metabolized to melamine in vivo [12]. The main adverse effects shown in studies on animals were kidney related, including renal calculi, renal tubular necrosis, crystalluria, and haematuria $[13,14]$.

The kidney is a vital organ, which plays an essential role in health, disease and overall development and growth. The main function of kidney is to maintain total body fluid volume, its composition and acid base balance. A number of environmental variables including certain xenobiotic influence these functions [15-17].

In fact, pesticides are known to increase the production of reactive oxygen species (ROS), which in turn generate oxidative stress in different tissues [18-20]. Many studies have implicated oxidative damage as the central mechanism of toxicity [21]. Oxidative damage primarily occurs through production of reactive oxygen species (ROS), including hydroxyl radicals and hydrogen peroxide that are generated during the reaction and react with biological molecules, eventually damaging membranes and other tissues [22]. Many insecticides are hydrophobic molecules that bind extensively to biological membranes, especially phospholipids bilayers [23], and they may damage membranes by inducing lipid peroxidation (LPO) $[4,20,24,25]$.

Herbal medicines derived from plant extracts are being increasingly utilized as adjunct treatment options for a wide variety of clinical disease. More attention has been paid to the protective effects of natural antioxidants against chemically induced toxicities [26]. The increasing interest in the health properties of tea extract and its main catechin polyphenols have led to a significant rise in scientific investigation for prevention and therapeutics in several diseases [27,28]. Crespy and Williamson [29] reported that green tea extract (GT) displays antioxidants and free radicals scavenger properties. Therefore the present study aimed to evaluate the oxidative damage and the renal toxicity of Cyr and/or CPF when administered orally to male rat as well as the ameliorating effect of green tea extract.

*Corresponding author: Abdel-Tawab H. Mossa, Environmental Toxicology Research Unit (ETRU), Pesticide Chemistry Department, National Research Centre (NRC), Cairo, Egypt, Tel: (202)-33371211/33371615; Fax: (202)-33370931; Mobile: 202 01005038504; E-mail: abdeltawab.mossa@yahoo.com

Received May 19, 2012; Accepted June 07, 2012; Published June 09, 2012

Citation: Heikal TM, Mossa ATH, Marei GIK, Abdel Rasoul MA (2012) Cyromazine and Chlorpyrifos Induced Renal Toxicity in Rats: The Ameliorating Effects of Green Tea Extract. J Environ Anal Toxicol 2:146. doi:10.4172/2161-0525.1000146

Copyright: ( 2012 Heikal TM, et al. This is an open-access article distributed under the terms of the Creative Commons Attribution License, which permits unrestricted use, distribution, and reproduction in any medium, provided the original author and source are credited. 


\section{Materials and Methods}

\section{Animals}

Healthy male Wistar rats weighing $143.5 \pm 1.11 \mathrm{~g}$ were obtained from the Animal Breeding House of the National Research Centre (NRC), Dokki, Cairo, Egypt and maintained in clean plastic cages (6 rats/cage) in the laboratory animal room $\left(23 \pm 2{ }^{\circ} \mathrm{C}\right)$. On standard pellet diet, tap water ad libitum, and daily dark/light cycle (12/12 hrs), the rats were acclimatized for 1 week prior to the start of experiments. The experimental work on rats was performed with the approval of the Animal Care \& Experimental Committee, National Research Centre, Cairo, Egypt, and international guidelines for care and use of laboratory animals.

\section{Chemicals}

Chlorpyrifos (97\%) and Cyromazine (99\%) were obtained from TaeGeuk Cop., South Korea. Pu-erh green tea of post-fermented tea produced in Yunnan province, China. The assay kits used for biochemical measurements of malondialdehyde (MDA), serum creatinine (Cre), catalase (CAT), superoxide dismutase (SOD) and glutathione peroxidase $(\mathrm{GPx})$ were purchased from Biodiagnostic, Egypt. However, the Blood Urea Nitrogen (BUN) kit was purchased from Stanbio Laboratory, Boerne, Texas, USA. All other chemicals were of reagent grades and were obtained from the local scientific distributors in Egypt.

\section{Preparation of green tea extract}

Likewise, the crude aqueous extract of green tea was prepared according to Maity et al. [30] and later adopted by El-Beshbishy [31] by soaking $15 \mathrm{~g}$ of instant green tea leaves in $1 \mathrm{~L}$ of distilled water whose temperature did not exceed $90^{\circ} \mathrm{C}$, for $5 \mathrm{~min}$ to obtain soluble polyphenols dissolved in the aqueous extract. The solution was filtered to obtain the final $1.5 \%(\mathrm{w} / \mathrm{v})$ green tea extract. This solution was substituted in the place of water as the sole source of drinking fluid.

\section{Experimental design}

Rats were randomly divided into 8 groups each containing 6 animals (6 rats/cage). The route of administration selected for the study was oral gavage for 28 consecutive days. Rats in Group I served as control and were given corn oil $(0.5 \mathrm{ml} / \mathrm{rat})$ and allowed distillate water ad libitum. Rats in Group II were given chlorpyrifos (CPF) in corn oil at a dose of $6.75 \mathrm{mg}$ a.i. $/ \mathrm{kg}$ b.wt. daily $\left(1 / 20 \mathrm{LD}_{50}\right)$ [32]. Rats in Group III were given cyromazine (Cyr) in corn oil at a dose of 169.35 $\mathrm{mg}$ a.i. $/ \mathrm{kg}$ b. wt. daily $\left(1 / 20 \mathrm{LD}_{50}\right)$ [32]. Rats in Group IV were given a combination of CPF (6.75 mg a.i. / kg b.wt.) and Cyr (169.35 mg a.i. / $/ \mathrm{kg}$ b. wt.). Rats in Group $\mathrm{V}$ where given aqueous green tea extract as the sole drinking fluid during the 28 days at a concentration of $1.5 \%(\mathrm{w} / \mathrm{v})$. Rats in Group VI, VII and VIII were given the same doses of pesticides as in groups II, III and IV, respectively and simultaneously allowed to an aqueous green tea extract as the sole source of drinking fluid. During the experimental duration, body weights were recorded and the doses modulated according to weekly body weight gain.

After completion of the treatment period, blood samples were centrifuged at $1500 \times \mathrm{g}$ for $10 \mathrm{~min}$ and the serum was removed and stored at $-20{ }^{\circ} \mathrm{C}$ for biochemical measurements by using Shimadzu UV- VIS Recording 2401 PC (Japan). Both kidneys were removed, cleaned and weighed for histological and biochemical evaluation.

\section{Preparation of homogenates}

After the completion of the experiment, the kidneys were removed, decapsulated and kept in ice-cold buffered saline (154 mM NaCl, $5 \mathrm{mM}$ Tris-HEPES, $\mathrm{pH} 7.5)$. A $10 \%(\mathrm{w} / \mathrm{v})$ homogenate was prepared in 0.1 $\mathrm{M}$ Tris- $\mathrm{HCl}$ buffer, $\mathrm{pH}$ 7.5, using Potter-Elvehejem homogenizer. The homogenate was centrifuged at $3000 \mathrm{xg}$ at $4{ }^{\circ} \mathrm{C}$ for $15 \mathrm{~min}$ to remove cell debris and the supernatant was saved in aliquots and stored at -20 ${ }^{\circ} \mathrm{C}$ for assaying protein concentration, lipid peroxidation (LPO) and antioxidant enzymes activity.

\section{Measurement of biochemical parameters}

The serum creatinine (Cre) and blood urea nitrogen (BUN) concentrations were measured spectrophotometrically at 495 and 600 $\mathrm{nm}$, respectively and expressed as $\mathrm{mg} / \mathrm{dl}$ by using commercial kits according to the instructions of the manufacturers.

\section{Oxidative stress evaluation}

Renal lipid peroxidation: Malondialdehyde (MDA) occurs in lipid peroxidation and was measured in kidney tissues after incubation at $95{ }^{\circ} \mathrm{C}$ with thiobarbituric acid in aerobic conditions ( $\mathrm{pH}$ 3.4). The pink colour produced by these reactions was measured spectrophotometrically at $532 \mathrm{~nm}$ to measure MDA levels [33].

\section{Renal antioxidant enzymes:}

- Assay of catalase (CAT): Catalase (CAT) activity was measured using the method of Aeibi [34]. Twenty $\mu$ l of the supernatant were added to a cuvette containing $780 \mu \mathrm{l}$ of $50 \mathrm{mM}$ potassium phosphate buffer ( $\mathrm{pH} 7.4)$ and then the reaction at $25^{\circ} \mathrm{C}$ was initiated by adding $200 \mu \mathrm{l}$ of $500 \mathrm{mM} \mathrm{H}_{2} \mathrm{O}_{2}$ to make a final volume of $1 \mathrm{ml}$. The decomposition rate of $\mathrm{H}_{2} \mathrm{O}_{2}$ was measured at $240 \mathrm{~nm}$ for $1 \mathrm{~min}$ on a spectrophotometer. A molar extinction coefficient of $0.0041 \mathrm{mM}^{-1}$ was used to determine the CAT activity. The activity was defined as an nmoles $\mathrm{H}_{2} \mathrm{O}_{2}$ decrease $/ \mathrm{min} / \mathrm{mg}$ protein.

- Assay of superoxide dismutase (SOD): Superoxide dismutase (SOD) activity was estimated according to Beauchamp and Fridovich [35]. The reaction mixture contained $50 \mathrm{mM}$ of kidney homogenates in $0.1 \mathrm{M}$ of potassium phosphate buffer (pH7.4), $0.1 \mathrm{mM}$ EDTA, $13 \mathrm{mM}$ L-methionine, $2 \mu \mathrm{M}$ riboflavin and $75 \mu \mathrm{M}$ Nitro Blue Tetrazolium (NBT). The developed blue color in the reaction was measured at $560 \mathrm{~nm}$. Units of SOD activity were expressed as the amount of enzyme required to inhibit the reduction of NBT by $50 \%$ and the activity was expressed as units per mg of protein.

- Assays of glutathione peroxidase (GPx): Glutathione peroxidase (GPx) activity was measured according to Flohe and Gunzler [36]. GPx catalyzes the oxidation of reduced glutathione by cumene hydroperoxide. In the presence of reduced glutathione reductase and nicotinamide adenine dinucleotide phosphate reduced form (NADPH), the oxidized reduced glutathione is immediately converted to the reduced form with a concomitant oxidation of NADPH to $\mathrm{NADP}^{+}$. The decrease in absorbance at $340 \mathrm{~nm}$ was measured. The enzyme activity was expressed as nmol of GSH oxidized/min/ mg protein. Protein concentration was determined according the method described by Lowry et al. [37] using bovine serum albumin (BSA) as a standard.

\section{Histopathological examination}

For light microscopic investigations, specimens from kidney were fixed in 10\% phosphate buffer formalin, dehydrated in alcohols and embedded in paraffin. Five micron tissue sections were stained with 
Citation: Heikal TM, Mossa ATH, Marei GIK, Abdel Rasoul MA (2012) Cyromazine and Chlorpyrifos Induced Renal Toxicity in Rats: The Ameliorating Effects of Green Tea Extract. J Environ Anal Toxicol 2:146. doi:10.4172/2161-0525.1000146

Page 3 of 7

hematoxylin and eosin stain (H\&E) for general histopathological examination [38]. Scoring of histopathological changes was done as follow: (-) absent; $(+)$ mild; $(++)$ moderate; $(+++)$ severe, and $(++++)$ extremely severe [38].

\section{Statistical analysis}

The results were expressed as means \pm S.E. All data were done with the Statistical Package for Social Sciences (SPSS 11.0 for windows). The results were analyzed using one way analysis of variance (ANOVA) followed by Duncan's test for comparison between different treatment groups. Statistical significance was set at $\mathrm{p}<0.05$.

\section{Results}

\section{Effect on the general health of rats}

During the experiment, no death was observed in any of the experimental groups. Rats in the control group and in green tea extract (GT) treated group did not show any sign of toxicity. However, CPF and $\mathrm{Cyr}+\mathrm{CPF}$ treated rats showed varying degrees of clinical signs few minutes after dosing. The signs included huddling, mild tremor and diarrhea. The observed signs were related to the cholinergic crisis; a consistent sign in organophosphate poisoning. Except for the huddling, no other significant clinical manifestation was observed following GT supplementation.

\section{Evaluation of body, absolute and relative kidney weights}

Our result showed that there was no significant difference in body, absolute and relative kidney weights between GT and untreated rats. However, body weight significantly decreased by $12 \%, 16 \%$ and $20 \%$ for Cyr, CPF and Cyr+CPF- treated groups, respectively. Relative kidney weight significantly increased by $14 \%, 13 \%$ \& $18 \%$ for Cyr,
$\mathrm{CPF}$ and $\mathrm{Cyr}+\mathrm{CPF}-$ treated groups, respectively when compared to control (Table 1). The administration of GT to pesticide treated groups ameliorated the loss of body weight and the increase of relative kidney weight in pesticide treated animals (Table 1).

\section{Renal lipid peroxidation (LPO)}

Administration of $\mathrm{Cyr}, \mathrm{CPF}$ and $\mathrm{Cyr}+\mathrm{CPF}$ led to a significant increase $(p<0.05)$ in lipid peroxidation as evidenced by the increase in kidney tissue MDA levels by 33,36 , and $44 \%$, respectively when compared to the control group. However, co-administration of GT to treated rats reduced the augmentation in MDA levels to 7, 10 and 19\% for Cyr, CPF and Cyr+CPF-treated rats, respectively (Table 2).

\section{Markers of renal function}

Serum creatinine level of $\mathrm{Cyr}, \mathrm{CPF}$ and $\mathrm{Cyr}+\mathrm{CPF}$-treated rats were higher $(57 \%, 52 \% \& 58 \%)$, respectively than those of control (Figure $1 \mathrm{~A})$, whereas, blood urea nitrogen (BUN) level were respectively, higher $(27 \%, 36 \% \& 40 \%)$ than those of control (Figure 1B). However, oral administration of GT to normal rats produced no changes in the cited above biochemical parameters when compared to the untreated control (Figure 1A,1B). Co-administration of GT to tested groups resulted in marked improvement in the level of Cre and BUN.

\section{Effects on activities of kidney antioxidant enzymes}

Results in Table 2 show the influence of Cyr, CPF and their combination on the activities of CAT, SOD and GPx. Subacute levels of the tested pesticides resulted in a state of kidney injury and extensive oxidative damage in rats as manifested by the significant alteration in these enzymes. In fact, in treated rats, a significant depletion was noted in the activities of CAT, SOD and GPx. However, the co-administration of GT mitigated the change in the activities of SOD, GPx and CAT (Table 2).

\begin{tabular}{|c|c|c|c|c|c|}
\hline \multirow{2}{*}{ Groups } & \multicolumn{3}{|c|}{ Body weight } & \multirow{2}{*}{ Absolute kidney weight (g) } & \multirow{2}{*}{$\begin{array}{l}\text { Relative kidney weight } \\
\text { (g/100g body weight) }\end{array}$} \\
\hline & Initial (g) & Final (g) & $\%$ Change/week & & \\
\hline Control & $142.8 \pm 0.85$ & $218.9 \pm 3.75^{\mathrm{ab}}$ & $8.68 \pm 0.26^{a}$ & $1.27 \pm 0.05$ & $0.58 \pm 0.012^{\mathrm{ab}}$ \\
\hline GT & $145.5 \pm 0.92$ & $221.9 \pm 4.19^{a}$ & $8.58 \pm 0.39^{a b}$ & $1.26 \pm 0.03$ & $0.57 \pm 0.089^{a}$ \\
\hline Cyr & $143.6 \pm 0.49$ & $191.0 \pm 7.36^{\text {cde }}$ & $6.10 \pm 0.70^{\mathrm{cd}}$ & $1.30 \pm 0.03$ & $0.68 \pm 0.014^{\mathrm{de}}$ \\
\hline CPF & $144.1 \pm 0.85$ & $183.92 \pm 3.35^{\mathrm{de}}$ & $5.39 \pm 0.32^{\mathrm{de}}$ & $1.24 \pm 0.03$ & $0.67 \pm 0.004^{d}$ \\
\hline Cyr+CPF & $142.8 \pm 0.85$ & $173.9 \pm 6.44^{\mathrm{e}}$ & $4.35 \pm 0.78^{\mathrm{e}}$ & $1.24 \pm 0.06$ & $0.71 \pm 0.016^{e}$ \\
\hline Cyr+GT & $145.0 \pm 0.60$ & $202.9 \pm 2.55^{\mathrm{bc}}$ & $7.12 \pm 0.23^{\mathrm{bc}}$ & $1.22 \pm 0.02$ & $0.60 \pm 0.004^{b}$ \\
\hline CPF+GT & $143.0 \pm 1.20$ & $195.9 \pm 7.99^{\mathrm{cd}}$ & $6.80 \pm 0.61^{\mathrm{cd}}$ & $1.24 \pm 0.03$ & $0.63 \pm 0.012^{c}$ \\
\hline Cyr+CPF +GT & $144.7 \pm 0.67$ & $192.18 \pm 7.40^{\mathrm{cd}}$ & $6.40 \pm 0.48^{\mathrm{cd}}$ & $1.21 \pm 0.04$ & $0.63 \pm 0.011^{c}$ \\
\hline
\end{tabular}

Each value is a mean of 6 rats \pm S.E.M; a, b, c, d values are not sharing superscripts letters $(\mathrm{a}, \mathrm{b}, \mathrm{c}, \mathrm{d})$ differ significantly at $p<0.05 ; \%$ of body weight change/week $=[($ final b .w t. - initial b .wt.)/ initial b .wt.]/no of weeks X 100; Cyr: Cyromazine; CPF: Chlorpyrifos; GT: Green tea.

Table 1: Effect of cyromazine and/or chlorpyrifos on body and relative kidney weights of rats and the ameliorative role of green tea.

\begin{tabular}{|l|c|c|c|}
\hline Treatments & $\begin{array}{c}\text { LPO } \\
\text { (nmoles/mg protein) }\end{array}$ & $\begin{array}{c}\text { CAT } \\
\text { (nmol/min/mg protein) }\end{array}$ & $\begin{array}{c}\text { SOD } \\
\text { (units/mg protein) } \\
\text { (nmoles of GSH oxidized/min/mg } \\
\text { protein) }\end{array}$ \\
\hline Control & $3.28 \pm 0.19^{\mathrm{a}}$ & $312.2 \pm 14.3^{\text {ab }}$ & $18.8 \pm 0.80^{\mathrm{a}}$ \\
\hline GT & $3.22 \pm 0.18^{\mathrm{a}}$ & $324.4 \pm 9.4^{\mathrm{a}}$ & $19.0 \pm 0.56^{\mathrm{a}}$ \\
\hline Cyr & $4.92 \pm 0.15^{\mathrm{c}}$ & $237.2 \pm 11.1^{\text {de }}$ & $12.0 \pm 0.90^{\text {cd }}$ \\
\hline CPF & $5.18 \pm 0.13^{\mathrm{c}}$ & $214.8 \pm 7.1^{\text {ef }}$ & $12.2 \pm 0.94^{\text {cd }}$ \\
\hline Cyr+CPF & $5.87 \pm 0.21^{\mathrm{d}}$ & $198.4 \pm 11.8^{\mathrm{f}}$ & $10.3 \pm 0.84^{\mathrm{d}}$ \\
\hline CPF+GT & $3.54 \pm 0.17^{\mathrm{a}}$ & $280.8 \pm 14.9^{\mathrm{bc}}$ & $2.95 \pm 0.09^{\mathrm{b}}$ \\
\hline Cyr+CPF +GT & $3.68 \pm 0.17^{\mathrm{ab}}$ & $265.6 \pm 11.8^{\mathrm{cd}}$ & $14.3 \pm 0.67^{\mathrm{bc}}$ \\
\hline
\end{tabular}

Each value is a mean of 6 rats \pm S.E.M; ${ }^{\text {a, b, c, d }}$ values are not sharing superscripts letters (a, b, c, d) differ significantly at $p<0.05$; Cyr: Cyromazine; CPF: Chlorpyrifos; GT: Green tea.

Table 2: Effect of cyromazine and/or chlorpyrifos on renal lipid peroxidation and antioxidant enzymes of male rats and the ameliorative role of green. 


\section{Histopathological examination}

The representative pictures of histopathological examination in the kidney tissue are shown in Figure $2(\mathrm{~A}-\mathrm{F})$ and the semi-quantitative histological scoring of liver damage is presented in Table 3. Kidney sections from the control group rats and green tea-treated rats showed intact histological structure of glomeruli and renal tubules. However, abnormalities in kidney of treated rats were detected in glomeruli and in convoluted tubules (Figure 2B-F) compared to those of controls (Figure 2A). The main characteristic findings were the appearance of vacuolization and swelling in the endothelium of glomerular tuft, swelling in the lining epithelium of tubules and inflammatory cells infiltration in between the degenerated tubules with fibrosis and hyalinosis between the tubules in focal manner. However, the co-administration of the GT with Cyr or CPF showed marked improvement in their histological structure in comparison to the treated groups (Cyr, CPF, Cyr+CPF) alone. Whereas, the severity of the above cited histological abnormalities ranged from nil to moderate degree and represented in Table 3.

\section{Discussion}

Intensive metabolic activity and multiple functions account for kidney's sensitivity to the action of toxicants. In the present study, oral administration of $\mathrm{CPF}$, Cyr or their combination of Cyr and

Serum creatinine

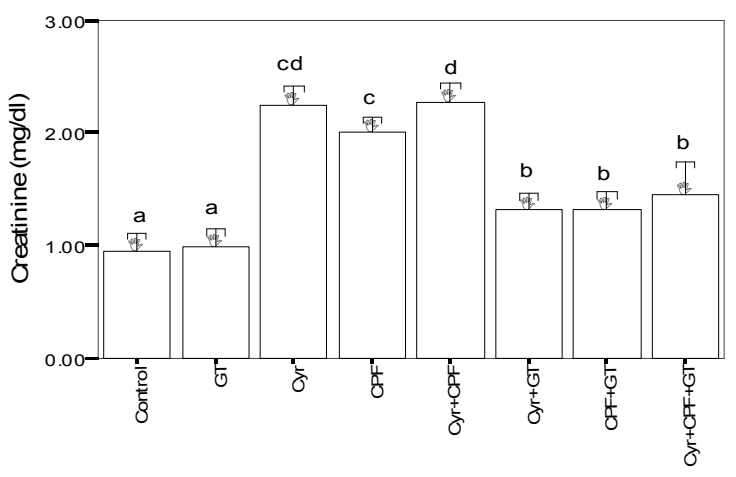

Blood urea nitrogen (BUN)

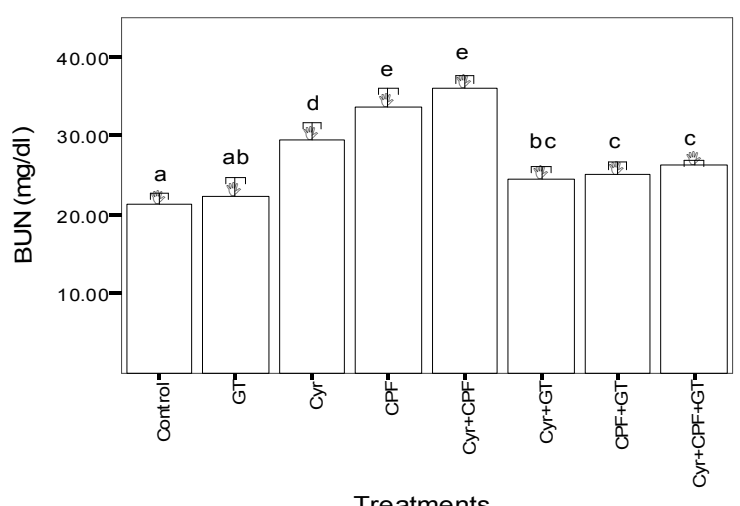

Treatments

Figure 1: Effect of exposure to Cyr, CPF and their combination on serum creatinine $(A)$ and blood urea nitrogen $(B)$ of rat in the absence and presence of GT. Data are expressed as mean \pm S.E.M of 6 rats. Columns are not sharing above letters (a, b, c, d, e) differ significantly at $p<0.05$; Cyr: cyromazine; CPF: chlorpyrifos, GT: green tea extract.

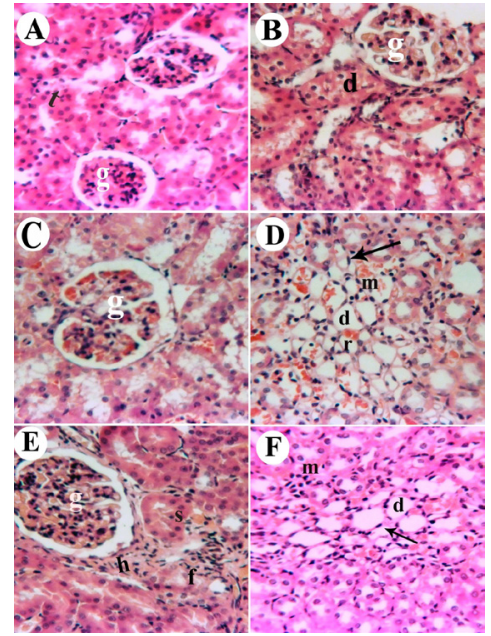

Figure 2: Kidney paraffin sections stained by haematoxylin and eosin (H\&E) for histopathological changes. Control group $[A]$ showing intact histological structure of glomeruli $(\mathrm{g})$ and renal tubules $(\mathrm{t})(\mathrm{x} 80)$, Cyr-treated group [B] showing vacuolization and swelling in the endothelium of glomerular tuft $(g)$ with swelling in the lining epithelium of tubules $(t)(x 80)$, CPF-treated group [C \&D] showing congestion in the tuft of the glomeruli $(\mathrm{g})(\times 80)$ and inflammatory cells infiltration $(m)$ in between the degenerated tubules (d), Cyr+CPF-treated group [E\&F] showing swelling and vacuolization in the endothelial cells lining the tuft of the glomeruli $(\mathrm{g})$ with fibrosis $(\mathrm{f})$ and hyalinosis $(\mathrm{h})$ between the tubules in focal manner and inflammatory cells infiltration $(\mathrm{m})$ and few fibroblastic cells proliferation (arrow) in between the degenerated tubules (d) in focal manner at the corticomedullary portion $(x 80)$.

CPF resulted in a significant reduction in the body weight gain, and an increase in the relative kidney weight. The reduction in body weight gains may be due to the combined action of cholinergic and oxidative stress [39-42] and/or due to the increased degradation of lipids and proteins as direct effects of organophosphate compound exposure $[19,43,44]$. Moreover, the increase in kidney weight could be attributed to the relationship between kidney weight increase and various toxicological effects or to the reduction in body weight gain of experimental animals [20,45-47]. This results are consistent with many previous investigators with CPF and other insecticides [19,20,42,4549]. Co-administration of GT improved body and kidney weights of intoxicated rats.

In the present study, the oral administration of CPF, Cyr or their combination to adult male rats provoked an increase in serum creatinine and blood urea nitrogen (BUN) levels of rats. It is well known that the kidney is the main site of elimination of xenobiotics [50]. Serum levels of BUN and Cre are used as indicators of renal function. These findings reflect the diagnosis of renal failure [51].

The potentially reactive derivatives of oxygen, ascribed as ROS such as $\mathrm{O}_{2}^{-}, \mathrm{H}_{2} \mathrm{O}_{2}$ and $\mathrm{OH}$ are continuously generated inside the human body as a consequences of exposure to a lot of exogenous chemicals in our ambient environment and/or a number of endogenous metabolic processes involving redox enzymes [52]. Under normal circumstances, the ROS generated are detoxified by the antioxidants present in the body and there is equilibrium between the ROS generated and the antioxidants present [52]. Harmful effects caused by ROS occur as a consequence of an imbalance between the formation and inactivation of these species. However, owing to ROS overproduction and/or inadequate antioxidant defense, this equilibrium is hampered favoring the ROS upsurge that culminates in oxidative stress [52]. Oxidative stress is through a series of events, dysregulate cellular physiology and 


\begin{tabular}{|c|c|c|c|c|c|c|c|c|}
\hline Treatments & Control & GT & Cyr & CPF & $\begin{array}{l}\text { Cyr } \\
+ \text { CPF }\end{array}$ & $\begin{array}{l}\text { Cyr } \\
+ \text { +GT }\end{array}$ & $\begin{array}{l}\text { CPF } \\
+ \text { +GT }\end{array}$ & Cyr+CPF +GT \\
\hline Swelling of endothelium of glomerular tuft & - & - & ++ & ++ & +++ & - & - & + \\
\hline $\begin{array}{l}\text { Vacuolization of endothelium of glomerular } \\
\text { tuft }\end{array}$ & - & - & ++ & + & ++ & + & - & - \\
\hline Congestion of glomeruli & - & - & ++ & + & ++ & - & - & - \\
\hline Degeneration in lining tubules & - & - & + & - & ++ & - & - & - \\
\hline Focal fibrosis between the tubules & - & - & - & - & ++ & - & - & - \\
\hline Hyalinosis between the tubules & - & - & - & + & + & - & - & + \\
\hline Inflammatory cells between the tubules & - & - & - & - & ++ & - & - & - \\
\hline Swelling in epithelium of lining tubules & - & - & - & - & ++ & - & - & + \\
\hline
\end{tabular}

Cyr: Cyromazine; CPF: Chlorpyrifos; GT: Green tea. (-) indicates normal, $(+)$ indicates mild, $(++)$ indicates moderate, $(+++)$ indicates severe, and (++++) indicates extremely severe.

Table 3: Semi-quantitative scoring of architectural damage on histopathological examination of the rat kidney in different treatment groups.

its sustained presence may lead to pathogenesis of several ailments [53]. The ROS readily attack and induce oxidative damage to various biomolecules including proteins, lipids, mitochondria, lipoproteins and DNA [54]. Oxidative stress affects many cellular functions by various mechanisms such as alteration in gene expression through activation of transcription factor NF-kB or induction of permeability transition in mitochondria with lethal consequences [55]. Our results revealed that the effect of exposure to CPF and/or Cyr for 28 days, in rats induced nephrotoxicity evidenced by histopathological observation and biochemical parameters perturbations in kidney of rats. This treatment has a negative effect on renal lipid peroxidation as well as the renal antioxidant defense system.

A significant increase in the LPO level following administration of the insecticides doses observed in the present study. Since ROS are highly reactive and can oxidize cellular macromolecules (e.g. lipids, DNA, nucleic acid and proteins) which may lead to genetic alterations. Lipid peroxidation is linked with excessive generation of ROS, which may be contributed by exogenous or endogenous sources and is the most destructive process in the living cells has been implicated in causing a wide range of biological effects such as increase membrane rigidity, osmotic fragility, decreased cellular deformation, reduced erythrocyte survival, and membrane fluidity [53,55]. Lipid peroxidation products, such as malondialdehyde and 4-hydroxy-2-nonenal (the most cytotoxic) cross link the membrane, damage the DNA and are mutagenic leading to functional changes [56]. Therefore, we used lipid peroxidation as a marker of oxidative stress and studied the effect of CPF and/or Cyr administration on renal lipid peroxidation. Treatments of animals with CPF and/or Cyr lead to the induction of lipid peroxidation, as monitored by measuring the rate of production of Thiobarbituric acid reactive substances (TBARS), expressed as malondialdehyde equivalents, reflecting the formation of activated species in rat kidney. These results are in line with the observation of previous researchers following OPIs administration [4,19,57]. Accumulation of lipid peroxide is believed to be a major contributor to the loss of cell function under oxidative stress conditions [56]. This further indicate that renal injury induced by CPF, Cyr and their combination in present study is the result of oxidative stress that arise as a result of excessive generation of ROS, which have been reported to attack various biological molecules including lipids and causing lipid peroxidation.

Results of the current study revealed that green tea extract (GT) reversed the elevation of lipid peroxidation. Hence, it is possible that the mechanism of green tea extract may be attributed to epicatechins (antioxidant present in green tea) that scavenge a wide range of free radicals including the most active hydroxyl radical, which may initiate lipid peroxidation. Therefore, it may decrease the concentration of lipid free radicals [58]. Moreover, it was reported previously that it chelates metal ions, especially iron and copper, which, in turn inhibit generation of hydroxyl radicals and degradation of lipid hydroperoxides [59].

Nephrotoxicity could also be explained by the impaired antioxidant enzyme activities in the kidney of the rats. Indeed, the antioxidant enzymes SOD, GPx and CAT limit the effects of oxidant molecules in tissues and act in the defense against oxidative cell injury by means of their being free radical scavengers [60]. These enzymes work together to eliminate active oxygen species. In this respect, $\mathrm{SOD}$ accelerates the dismutation of $\mathrm{H}_{2} \mathrm{O}_{2}$, also termed as a primary defense, as it prevents further generation of free radicals whereas, CAT helps in the removal of $\mathrm{H}_{2} \mathrm{O}_{2}$ formed during the reaction catalyzed by SOD [61]. In the current study, our results indicated that $\mathrm{CPF}$ and/or Cyr exposure inhibited SOD, CAT and GPx activities in kidney of rat. This depletion may be due to the decreased synthesis of enzymes or oxidative inactivation of enzyme protein.

Our histopathological data substantiate kidney dysfunction. Indeed, the renal histoarchitecture of the CPF, Cyr and CPF+Cyrtreated rats showed swelling in the endothelium of glomerular tuft, swelling in the lining epithelium of tubules and inflammatory cells infiltration in between the degenerated tubules.

Most of the biochemical alterations accompanied by histopathological changes were alleviated following GT administration. This could be attributed to the antioxidant capacity of GT that reduce the lipid peroxidation which in turn restore the integrity of the cell membrane and improve the disturbance in permeability.

Since the oxidative damage as the central mechanism of pesticides toxicity occurs primarily through production of reactive oxygen species (ROS), including hydroxyl radicals and hydrogen peroxide that are generated during the reaction and react with biological molecules, eventually damaging membranes and other tissues [21,22]. The use of antioxidants to counteract the formed ROS is the corner stone in alleviation of such hazards. So, the major nutraceutical compounds in green teas are tea catechins that have the most effective antioxidant activity. Tea catechins are an efficient free radical scavenger due to their one electron reduction potential $[62,63]$. In addition, tea contains minerals that function as co-factors in antioxidant enzymes: zinc, selenium and manganese. Polyphenols have additional mechanisms in which they reduce oxidation level besides direct role as antioxidants: (1) Binding of metal ions such as iron and copper and preventing their participation in oxidation reactions (leading to the formation of hydroxyl radical). (2) Prevention of redox sensitive transcription factors activation that amongst others things serve as mediators of 
Citation: Heikal TM, Mossa ATH, Marei GIK, Abdel Rasoul MA (2012) Cyromazine and Chlorpyrifos Induced Renal Toxicity in Rats: The Ameliorating Effects of Green Tea Extract. J Environ Anal Toxicol 2:146. doi:10.4172/2161-0525.1000146

Page 6 of 7

inflammatory reactions. (3) Suppression of oxidation stimulants such as induced nitric oxide synthase (iNOS), cyclooxygenase 2 (COX2), lipoxygenase 2 (LOX-2) and xanthine oxidase. (4) Induction of antioxidant enzymes such as glutathione S-transferase and super oxide dismutase [64].

\section{Conclusion}

The results of present study show that Cyr and CPF treatments caused oxidative damage, biochemical and histopathological alterations in the kidney of male rats. In contrast GT reduces oxidative damage by virtue of its antioxidant properties thus improving the structural integrity of cell membrane and eventually alleviates the histopathological changes as well as the biochemical perturbations. Based on our present observations, we propose that GT may provide a cushion for prolonged therapeutic option against toxins-induced nephrotoxicity without harmful side effects.

\section{Acknowledgement}

The authors are grateful of Prof. Dr. Adel Mohamed Bakeer Kholoussy, Professor of Pathology, Faculty of Veterinary Medicine, Cairo University for interpreting the histopathological sections.

\section{References}

1. Cetin N, Cetin E, Eraslan G, Bilgili A (2007) Chlorpyrifos induces cardiac dysfunction in rabbits. Res Vet Sci 82: 405-408.

2. WHO (1997) The WHO recommended classification of pesticides by hazard and guidelines to classification 1996-1997, International programme on chemical safety, WHO/IPCS/96.3.

3. Mutch E, Williams FM (2006) Diazinon, chlorpyriphos and parathion are metabolised by multiple cytochromes P450 in human liver. Toxicology 224 : 22-32.

4. Mansour SA, Mossa AH (2009) Lipid peroxidation and oxidative stress in rat erythrocytes induced by chlorpyrifos and the protective effect of zinc. Pest Bioch Physiol 93: 34-39.

5. Tripathi S, Srivastav AK (2010) Liver profile of rats after long-term ingestion of different doses of chlorpyrifos. Pest Bioch Physiol 97: 60-65.

6. Khan SM, Kour G (2007) Subacute oral toxicity of chlorpyrifos and protective effect of green tea extract. Pest Bioch Physiol 89: 118-123.

7. Uzun FG, Kalender S, Durak D, Demir F, Kalender Y (2009) Malathion-induced testicular toxicity in male rats and the protective effect of vitamins $\mathrm{C}$ and $\mathrm{E}$. Food Chem Toxicol 47: 1903-1908.

8. Saulsbury MD, Heyliger SO, Wang K, Johnson DJ (2009) Chlorpyrifos induces oxidative stress in oligodendrocyte progenitor cells. Toxicology 259: 1-9.

9. Demir F, Uzun FG, Durak D, Kalender Y (2011) Subacute chlorpyrifos-induced oxidative stress in rat erythrocytes and the protective effects of catechin and quercetin. Pest Bioch Physiol 99: 77-81.

10. Graf JF (1993) The role of insect growth-regulators in arthropod control. Parasitol Today 9: 471-474.

11. The agrochemicals handbook (1993) $2^{\text {nd }}$ edn. Royal Society of Chemistry. Surry, UK: Unwin Brothers Limited.

12. Keiding J (1999) Review of the global status and recent development of insecticide resistance in field populations of he housefly, Musca domestica (Diptera: Muscidae). Bull Entomol Res 89: 9-67.

13. Cianciolo RE, Bischoff K, Ebel JG, Van Winkle TJ, Goldstein RE, et al. (2008) Clinicopathologic, histologic, and toxicologic findings in 70 cats inadvertently exposed to pet food contaminated with melamine and cyanuric acid. J Am Vet Med Assoc 233: 729-737.

14. Dobson RL, Motlagh S, Quijano M, Cambron RT, Baker TR, et al. (2008) Identification and characterization of toxicity of contaminants in pet food leading to an outbreak of renal toxicity in cats and dogs. Toxicol Sci 106: 251-262.

15. Mahmood I, Waters DH (1994) A comparative study of uranyl nitrate and cisplatin-induced renal failure in rat. Eur J Drug Metab Pharmacokinet 19: 327-336.
16. Begg EJ, Barclay ML (1995) Aminoglycisides-50 years on. Br J Clin Pharmaco 39: 597-603.

17. Fatima S, Yusufi AN, Mahmood R (2004) Effect of cisplatin on renal brush border membrane enzymes and phosphate transport. Hum Exp Toxicol 23 547-554.

18. Rai DK, Sharma B (2007) Carbofuran induced oxidative stress in mammalian brain. Mol Biotechnol 37: 66-71.

19. Heikal TM, Soliman MS (2010) Effect of fish oil supplementation on brain DNA damage and hepatic oxidant/antioxidant status in dimethoate-treated rats. J Egypt Soc Toxicol 42: 1-9.

20. Heikal TM, Ghanem HZ, Soliman MS (2011) Protective effect of green tea extracts against dimethoate induced DNA damage and oxidant/antioxidant status in male rats. Biohealth Science Bulletin 3: 1-11.

21. Halliwell B, Gutteridge JMC (2002) Free Radicals in Biology and Medicine. 3rd edn. Oxford: University Press Inc 105-245.

22. Vuillaume M (1987) Reduced oxygen species, mutation, induction, and cancer initiation. Mutat Res 186: 43-72.

23. Ogutcu A, Suludere Z, Kalender Y (2008) Dichlorvos-induced hepatotoxicity in rats and the protective effects of vitamins $C$ and $E$. Environ Toxicol Pharmacol 26: 355-361.

24. Celik I, Yilmaz Z, Turkoglu V (2009) Hematotoxic and hepatotoxic effects of dichlorvos at sublethal dosages in rats. Envir Toxicol 24: 128-132.

25. Kalender S, Uzun FG, Durak D, Demir F, Kalender Y (2010) Malathion-induce hepatotoxicity in rats: the effects of vitamin $C$ and $E$. Food Chem Toxicol 48 633-638.

26. Frei B, Higdon JV (2003) Antioxidant activity of tea polyphenols in vivo: evidence from animal studies. J Nutr 133: 3275-3284.

27. Mandel S, Weinreb O, Reznichenk L, Kafon L, Amit T (2006) Green tea catechins as brain- permeable, non toxic iron chelators to 'iron out iron' from the brain. J Neural Transm Suppl 71: 249-257.

28. Ostrowska J, Skrzydlewska E (2006) The comparison of effect of catechins and green tea extract on oxidative modification of LDL in vitro. Adv Med Sci 51: 298-303.

29. Crespy V, Williamson G (2004) A review of the health effects of green tea catechins in in vivo animal models. J Nutr 134: $3431-3440$.

30. Maity S, Vadasiromoni JR, Ganguly DK (1998) Role of glutathione in the antiulcer effect of hot water extract of black tea. Jpn J Pharmacol 78: 285-292.

31. El-Beshbishy HA (2005) Hepatoprotective effect of green tea (Camellia sinensis) extract against tamoxifen-induced liver injury in rats. J Biochem Mo Biol 38: 563-570.

32. Tomlin, CDS (2004) The e-Pesticide Manual Version 3.1. London, UK: The British Crop Protection Council.

33. Ohkawa H, Ohishi N, Yagi K (1979) Assay for lipid peroxides in animal tissues by thiobarbituric acid reaction. Anal Biochem 95: 351- 358

34. Aebi H (1984) Catalase in vitro. Methods Enzymol. 105: 121-126.

35. Beauchamp C, Fridovich I (1971) Superoxide dismutase: improved assays and an assay applicable to acrylamide gel. Anal Biochem 44: 276-287.

36. Flohe L, Gunzler WA (1984) Assays of glutathione peroxidase. Methods Enzymol 105: 114-121.

37. Lowry OH, Rosebrough NJ, Farr AL, Randall RJ (1951) Protein measurement with the Folin phenol reagent. J Biol Chem 193: 265-275.

38. Bancroft GD, Stevens A, Turner DR (1996) Theory and practice of technique $4^{\text {th }}$ edn. New York: Churchill Livingston.

39. Mansour SA, Mossa AH (2010) Adverse effects of lactational exposure to chlorpyrifos in suckling rats. Hum Exper Toxicol 29: 77-92.

40. Grance SR, Teixeira MA, Leite RS, Guimarães EB, de Siqueira JM, et al. (2008) Baccharis trimera: effect on hematological and biochemical parameters and hepatorenal evaluation in pregnant rats. J Ethnopharmacol 117: 28-33.

41. Dirican EK, Kalender Y (2011) Dichlorvos-induced testicular toxicity in male rats and the protective role of vitamins $\mathrm{C}$ and $\mathrm{E}$. Exp Toxicol Pathol.

42. Saafi EB, Louedi M, Elfeki A, Zakhama A, Najjar MF, et al. (2011) Protective 
Citation: Heikal TM, Mossa ATH, Marei GIK, Abdel Rasoul MA (2012) Cyromazine and Chlorpyrifos Induced Renal Toxicity in Rats: The Ameliorating Effects of Green Tea Extract. J Environ Anal Toxicol 2:146. doi:10.4172/2161-0525.1000146

effect of date palm fruit extract (Phoenix dactylifera L.) on dimethoate inducedoxidative stress in rat liver. Exp Toxicol Pathol 63: 433-441.

43. Goel A, Dani V, Dhawan DK (2005) Protective effects of zinc on lipid peroxidation, antioxidant enzymes and hepatic histoarchitecture in chlorpyrifosinduced toxicity. Chem Biol Interact 156: 131-140.

44. Mossa A H, Refaie AA, Ramadan A (2011) Effect of Exposure to Mixture of Four Organophosphate Insecticides at No Observed Adverse Effect Level Dose on Rat Liver: The Protective Role of Vitamin C. Res J Envir Toxicol 5: 323-335.

45. Amacher DE, Schomaker SJ, Burkhardt JE (1998) The relationship among microsomal, enzyme induction, liver weight and histological change in rat toxicology studies. Food Chem Toxicol 36: 831-839.

46. Chung MK, Kim JC, Han SS (2002) Developmental toxicity of flupyrazofos, a new organophosphorous insecticide in rats. Food Chem Toxicol 40: 723-729.

47. Mansour SA, Heikal TM, Refaie AA, Mossa AH (2011) Antihepatotoxic activity of fennel (Foeniculum vulgare Mill.) essential oil against chlorpyrifos-induced liver injury in rats. Global J. Envir. Sci. Technol. 1: 1-10.

48. Troudi A, Soudani N, Mahjoubi Samet A, Ben Amara I, Zeghal N (2011) 2,4-Dichlorophenoxy acetic acid effects on nephrotoxicity in rats during late pregnancy and early postnatal periods. Ecotoxicol Environ. Saf 74: 2316-2323.

49. Sharma Y, Bashir S, Irshad M, Nag TC, Dogra TD (2005) Dimethoate-induced effects on antioxidant status of liver and brain of rats following subchronic exposure. Toxicology 215: 173-181.

50. Matos RC, Vieira C, Morais S, de Lourdes Pereira M, de Jesus JP (2009) Nephrotoxicity of CCA-treated wood: A comparative study with $\mathrm{As}(2) \mathrm{O}(5)$ and $\mathrm{CrO}(3)$ on mice. Environ Toxicol Pharmacol 27: 259-263.

51. Donadio C, Lucchesi A, Tramonti G, Bianchi C (1997) Creatinine clearance predicted from body cell mass is a good indicator of renal function. Kidney Int Suppl 63: 166-168.

52. Sun $Y(1990)$ Free radicals, antioxidant enzymes and carcinogenesis. Free Radic Biol Med 8: 583-599.

53. Hogg N (1998) Free radicals in disease. Semin Reprod Endocrinol 16: $241-$ 288.
54. Faber JL (1994) Mechanism of cell injury by activated oxygen species. Environ Health Perspect 102: 17-24.

55. Kaplowitz N, Tsukamoto H (1996) Oxidative stress and liver disease. Prog Liver Dis 14: 131-159.

56. Iqbal M, Giri U, Giri DK, Alam MS, Athar M (1999) Age-dependent rena accumulation of 4-hydroxy-2-nonenal (HNE)-modified proteins following parenteral administration of ferric nitrilotriacetate commensurate with its differential toxicity: implications for the involvement of HNE-protein adducts in oxidative stress and carcinogenesis. Arch Biochem Biophys 365: 101-112.

57. Mansour SA, Mossa AH (2010) Oxidative damage, biochemical and histopathological alterations in rats exposed to chlorpyrifos and the antioxidant role of zinc. Pest Bioch Physiol 96: 14-23.

58. Skrzydlewska E, Ostrowska J, Stankiewicz A, Farbiszewski R (2002) Green tea as a potent antioxidant in alcohol intoxication. Addict Biol 7: 307-314.

59. Azram S, Hadi N, Khan NU, Hadi SM (2004) Prooxidant property of green tea polyphenols, epicatechin and epicatechin- 3-gallate: implications of anticancer properties. Toxicol In Vitro 18: 555-561.

60. Halliwell, B, Gutteridge JMC (2001) Detection of free radicals and other reactive species: trapping and fingerprinting. In: Halliwell, B., Gutteridge, J.M.C. (Eds.), Free Radicals in Biology and Medicine. Oxford University Press, Oxford 351425

61. Liu CM, Zheng YL, Lu J, Zhang ZF, Fan SH, et al. (2010) Quercetin protects rat liver against lead-induced oxidative stress and apoptosis. Environ Toxicol Pharmacol 29: 158-166

62. Higdon JV, Frei B (2003) Tea catechin and polyphenols: Health effects metabolism and antioxidant functions. Crit Rev Food Sci Nutr 43: 89-143.

63. Dubick M A, Omaye S T (2007) Grape wine and tea polyphenols in the modulation of atherosclerosis and heart disease. In R E. C. Wildman (Edn.), Handbook of nutraceuticals and functional foods. $2^{\text {nd }}$ edn. Boca Raton: CRC Press.

64. Cabrera C, Artacho R, Gimenez R (2006) Beneficial effects of green tea - a review. J Am Coll Nutr 25: 79-99. 